artigo $] \begin{aligned} & \text { [ EVELISE ANICET | LUIZ MARCELO STRALIOTTO ] } \\ & \begin{array}{l}\text { Evelise Anicet é coordenadora do Núcleo de Design de Superficie da UFRGS, } \\ \text { orientadora no Mestrado em Design da mesma instituiçăo e pesquisadora do }\end{array}\end{aligned}$ CNPq. É designer do Studio Surface e do Ateliê Contextura. Bacharel e mestre em Artes Visuais, é doutora em Informática na Educação pela UFRGS.

E-mail: anicet@ufrgs.br

Luiz Marcelo Straliotto é bacharel em Artes Plásticas e mestre em Design pela UFRGS, especialista em Design Gráfico pela Unisinos. Atualmente é professor no Núcleo de Design de Superficie da UFRGS e designer de joias da Argefnteria \& Ourivesaria Gaudencio Orso.

E-mail: straliotto@hotmail.com

\title{
A bola da moda
}

\section{The fashion ball}

[resumo] Este artigo trata de alguns aspectos de mútua influência entre o mundo esportivo e a moda, discutindo sobre o design de superfície tradicionalmente aplicado sobre bolas, e propõe novas soluções gráficas.

\section{[palavras-chave}

moda; design; superfície; bola.

[abstract] This article deals with some aspects of mutual influence of the sports world and fashion. It also discusses on the traditional surface design applied on the ball surfaces and proposes innovative graphic solutions.

[key words] fashion; design; surface; ball.

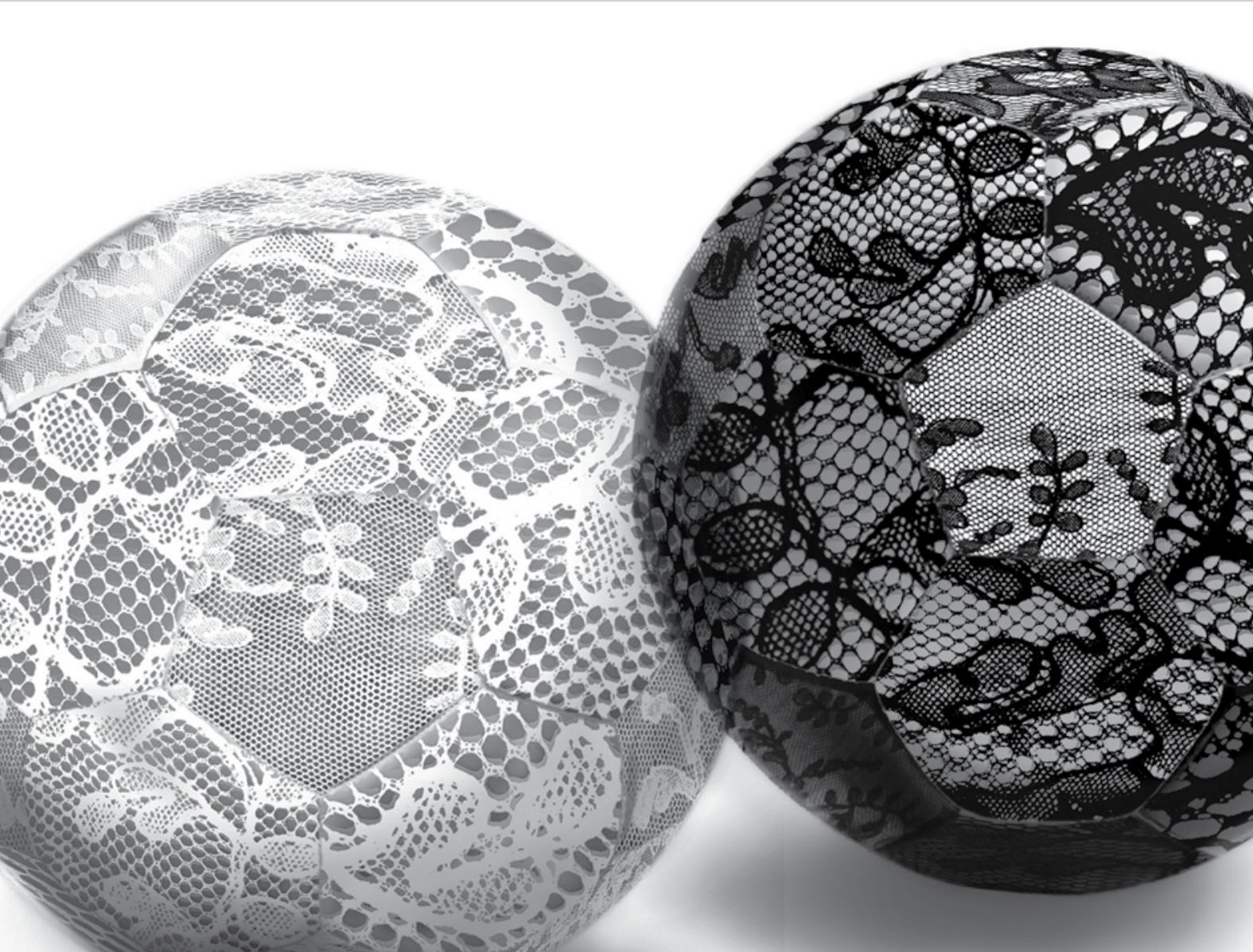




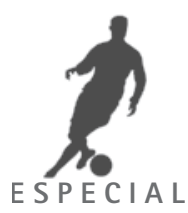

Fibras de bambu entrelaçadas, novelo de cabelo feltrado, bexiga de boi cheia de areia constituem os ancestrais da bola na Antiguidade.

Foram identificados por historiadores vestígios dos jogos de bola em várias culturas antigas como China, Japão e Grécia, que transferiu o hábito de jogar bola aos romanos. Da Itália medieval o gioco del cálcio chegou à Inglaterra onde o jogo se tornou menos violento e mais organizado dentro de regras definidas quanto à maneira de jogar, número de jogadores, tamanho e forma do campo, contendo dois arcos retangulares colocados em cada extremidade, chamados de gol. A bola era de couro e bexiga de porco enchida com ar.

Uma vez sistematizado, o jogo passou a ser, pouco a pouco, assimilado pelos nobres e pelo povo. As regras evoluiam gradativamente e, em 1885, na Inglaterra, teve início o profissionalismo no futebol. Em 1904, foi criada a Federação Internacional de Futebol Associado (Fifa), entidade que organiza até hoje o futebol em todo o mundo. Da mesma forma, surgiram em cada país instituições que regem as normas e os campeonatos.

Com a ocorrência sistemática de eventos esportivos oficiais, a bola passou a ter, basicamente, dois padrões diferentes: as profissionais e as amadoras. As chamadas bolas oficiais, que são usadas em partidas oficiais e/ou profissionais, possuem características como: tamanho, acabamento, cor, material, peso, agarre etc., controladas com rigor pelo órgão responsável, como garantia de neutralidade entre os jogos de um mesmo torneio.

Por outro lado, a cultura popular do brincar com bola, que é global, mas muito mais brasileira, é praticada por adultos e crianças, homens e mulheres, manifesta-se em todas as classes sociais e de diferentes maneiras de jogar. Nesse caso, as bolas adquirem características físicas livres, como cores, texturas e materiais utilizados de acordo com o público e o desempenho esperado do objeto lúdico.

Apesar de não haver cerceamento na definição da aparência das bolas não oficiais, nota-se que permanece alinhada ao padrão de composição visual tradicional dos artigos esportivos. Observa-se, hoje, que a estética adotada nos tratamentos de superfície das bolas fabricadas para o público amador se mantém aderida ao legado da heráldica, essa herança medieval da linguagem dos brasões e emblemas que designam bandeiras de paises e/ou de times, e se apresenta como solução gráfica sintética, utilizando poucas cores dispostas em blocos com a sobreposição de logotipos impressos sobre as bolas.

Até pouco tempo, o legado visual era reforçado por limitações técnicas nos processos de transferência de desenhos para superfície das bolas. Hoje o cenário mudou e novos recursos estão disponíveis.

Dentro da classificação não oficial existem as chamadas bolas comemorativas, que são oferecidas ao mercado por ocasião de grandes eventos desportivos, como a Copa do Mundo, e até mesmo pelo desempenho dos times nos campeonatos locais. 0 fato é que passou a ser usual a estratégia de marketing em que os clubes dos times vendem ao público bolas com suas marcas impressas. Isso se tornou uma oportunidade de arrecadação de renda importante na contabilidade dos clubes. Tratando-se de estratégia comercial, talvez seja comparável à venda de perfumes das grandes grifes.

É interessante notar que pesquisas recentes de mercado brasileiro mostram que a maioria das bolas vendidas nessa categoria não é usada para jogar. De maneira geral, as pessoas as compram para dar de presente - para filho, filha, amigo, afilhado. Apesar de ser um presente valorizado, grande parte das bolas fica exposta em prateleiras no interior das residências, de onde podem ser vistas constantemente, como uma 
maneira de fortalecer a vibração que o indivíduo sente pelo seu time.

0 fascínio exercido pela bola tem a ver com sua forma redonda que, além de promover muitos usos e movimentos, traz diversas significações. É considerada uma forma perfeita da natureza e tem sido, durante a história, ocupação de filósofos, pedagogos, psicólogos, dentre outros estudiosos.

0 futebol como jogo popular é aprendido dentro do grupo social a que pertence o sujeito, suprindo a necessidade coletiva de recreação. A bola é o elemento disparador do processo de mover e ser movido, provocando agilidade em todos os participantes a partir de ação-reação, até a recriação.

Essa palavra mágica - recriação - foi o que motivou o trabalho em parceria com a empresa detentora dos direitos da marca Peacock Sports ${ }^{1}$ no Brasil. De posse de pesquisas de mercado e análises de cenário socioeconômico, a empresa identificou a falta de desenhos criativos para bolas.

A causa está na aderência aos padrões esportivos preestabelecidos, que inibe a formação de novas ideias, assim como a barreira da inércia cultural que não deixa perceber que há hoje condições de propor novas visualidades, uma vez que existem meios de serem fabricadas.

A Peacock Sports fundamentou o lançamento das suas bolas explorando a lacuna no mercado de bolas com desenhos inovativos. Vale destacar que a evolução dos sistemas produtivos está acelerada, oferecendo novos recursos técnicos para impressão de imagens com novas linguagens. Dentro desse contexto, a empresa lançou, em 2009, um concurso de design de superfície de bolas denominado Sua bola, sua ideia para alunos de cursos de design, artes, moda, publicidade e áreas afins. Num primeiro momento, a proposta causou estranhamento, mas o fomento à criatividade deve seguir como uma bandeira da empresa, considerando que o mercado de bolas no Brasil é atualmente de 10 milhões de bolas por ano, com tendência a aumentar, tendo em vista a Copa do Mundo na África do Sul, em 2010, e no Brasil, em 2014, e as Olimpiadas no Brasil, em 2016.

Deve-se levar em conta que nenhuma outra nação se prepara com tanta euforia para um campeonato mundial de futebol como o Brasil. Nunca se falou tanto em futebol como atualmente. Isso motiva os designers a proporem inovações nas soluções gráficas para as superfícies das bolas, rompendo com os padrões tradicionais adotados até então.

Com o intuito de estimular a criatividade e o domínio dos métodos de desenvolvimento de projetos de design de superfície, apresentamos a seguir um exercício conceitual de aproximação entre moda e futebol.

\section{A bola vestida}

A partir da constatação de que as estampas usadas nas superfícies das bolas fazem parte da tradição esportiva totalmente assimilada pela população, foi importante compreender os principais sentimentos que 
estão representados: o espírito de time, a rivalidade, a raça do torcedor, a disputa dos clubes, a grandiosidade das olimpíadas, a superação do homem quando o atleta se torna quase divino e a catarse do esporte.

Na relação entre futebol e moda, num contexto recente, observam-se dois movimentos: um que é o da moda influenciada pelo mundo esportivo, e outro, bem mais novo, que é o movimento do mundo esportivo buscando a moda.

No primeiro tipo de deslocamento, a moda apoia-se na linguagem esportista para atender um estilo de vida contemporâneo e acaba por reforçar o padrão preestabelecido de soluções estéticas. Segundo Queiroz (2009, p. 56), que credita esse fato ao desejo do homem se vestir como herói,

\footnotetext{
Há mais de trinta anos a moda se apodera das cores, das formas e dos materiais dos uniformes esportivos. Muitos itens saíram das quadras para fazerem parte do guarda-roupa cotidiano. 0 maior exemplo está nos calçados: os tênis cada vez mais substituem os sapatos. (...) Marcas ligadas ao esporte ampliaram suas áreas de atuação e chegaram a competir com grifes de moda.
}

Queiroz (2009) acrescenta que principalmente a moda masculina tem por hábito produzir camisetas e blusões com estampas e bordados com emblemas de times de futebol.

Por outro lado, a parceria de Stella McCartney e Adidas estabelece um deslocamento no sentido contrário, da moda para o esporte. A estilista inglesa utiliza métodos alternativos de construção de roupas, como a gradual substituição da costura pela colagem têxtil. Apoiada pela alta tecnologia disponível em processos industriais de produção de tecidos e de vestuário, cria dentro de seu estilo uma nova visualidade para artigos esportivos. Propõe coleções com palheta de cores pastel, estampas orgânicas, toques suaves e formas alternativas, completamente livres do estabelecido no mundo dos esportes. Muda a estética e aprimora a funcionalidade, gerando novo padrão de gestos e comportamentos. É a mudança de paradigma para um mundo que utiliza a tecnologia para poder ter o melhor: o natural, o conforto e desempenho, sem abrir mão da estética nem da consciência ambiental.

\footnotetext{
0 bom design traduzirá, assim, as necessidades pessoais, os instintos remotos e os desejos confessáveis, nos ajudando a buscar refúgio solitário ou no aconchego de doce companhia; nos fornecerá bem-estar físico e alivio psicológico durante as jornadas marcadas pelos conflitos; será nosso aliado na obtenção de energias renováveis que garantirão o cuidado da nossa vida e a preservação do planeta. (GORETTI, 2010, p. 11)
}

Essas constatações dizem respeito às roupas e aos acessórios esportivos. Quanto às bolas, foram encontrados novos desenhos, de alta qualidade criativa, de marcas reconhecidas no setor, que demonstram a liberdade dada pelos novos recursos produtivos, mas não foram encontrados projetos de design de superfície de bolas que instaurassem uma nova estética.

\section{Exercício conceitual}

0 capitalismo transformou os cidadãos em consumidores passivos. Esse fato, aliado à magia exercida sobre o público pelo espetáculo de mídia - o futebol -, estabelece uma barreira às mudanças. Para provocar a ruptura do que já é convencional, é preciso se inspirar nos modernistas e propor um "choque do novo" a fim de despertar a participação ativa do público, discutindo o preestabelecido e propondo novas imagens para tratamentos de superfícies.

0 estudo foi complementado com um exercício conceitual de aplicação prática de uma nova visualidade para superfícies das bolas. A proposta procurou seguir a lógica inversa do domínio masculino, colocando a pergunta: E se o mundo delicado feminino pedisse uma revanche e impusesse a sua moda ao mundo do futebol? Uma insensatez! Diriam muitos. "Coisa de mulherzinha!"

Brincadeira à parte, cabe considerar o crescente interesse feminino pelo esporte. 
Ethel Leon destaca: "A marca das duas traves retira o futebol do exclusivo universo masculino, acentua o vazio do campo, que o jogo, de homens ou mulheres, deve preencher"2.

0 objetivo aqui é o de apenas provocar a reflexão sobre essas questões, buscando desconstruir o status quo, propor a liberdade criativa, abrir novas possibilidades de trabalho para os designers e ofertar ao mercado produtos "divertidos", na contramão da rivalidade proposta pelo jogo.

Para fazer frente a símbolos tão sedimentados na cultura popular, foi eleito para o trabalho outro ícone campeão na representação do universo feminino: a renda. Este tecido delicado e transparente se mantém sempre em moda, pois evoca fortemente qualidades e características de romantismo e inocência, especialmente na cor branca. Mas, quando a cor é preta, a mesma renda remete ao fetiche e à sensualidade.

A partir desse contexto conceitual, foi desenvolvido um projeto contemplando a negociação entre efeito visual desejado e restrições de processos produtivos e de materiais usados.

Num primeiro momento elegeram-se as rendas artesanais brasileiras, mas, posteriormente, foram substituidas pelas rendas referenciadas em rendas francesas, por terem maior poder semântico no inconsciente coletivo. A mensagem deveria ser direta e focada em contrapor o masculino, e não valorizar nosso artesanato.

A proposta era ter uma bola de renda que tivesse o desempenho das bolas comuns. 0 projeto teve início pela composição da textura visual da bola em que é necessária a simulação virtual, instrumento normalmente adotado para apresentar ao cliente a solução gráfica antes mesmo de ser executada. Depois da aprovação da ideia pelo cliente, parte-se para a execução do desenho técnico, que é distribuído sobre 0 molde planificado da bola, a qual é composta de 32 gomos, dos quais 12 pentágonos e 20 hexágonos.

A complexidade do molde, bem como os motivos florais intrincados das rendas, sugere a construção de um patchwork, no qual cada gomo recebe um retalho de renda diferente, com maior ou menor detalhamento, sem preocupação de continuidade entre os gomos ou módulos, buscando o contraste, a fragmentação e desconstrução dos padrões decorativos. 0 resultado final elege a composição mais expressiva para 0 modelo tridimensional, como uma moulage virtual.

A construção da imagem parte da digitalização das rendas, que geram imagens bitmaphiper-realistas. 0 próximo passo é a redução de cores para atender aos limites do processo de serigrafia, sem perder a qualidade ilusória. Importante ressaltar que o resultado obtido é a simulação de um produto em desenvolvimento, portanto os produtos finalizados poderão ser diferentes.

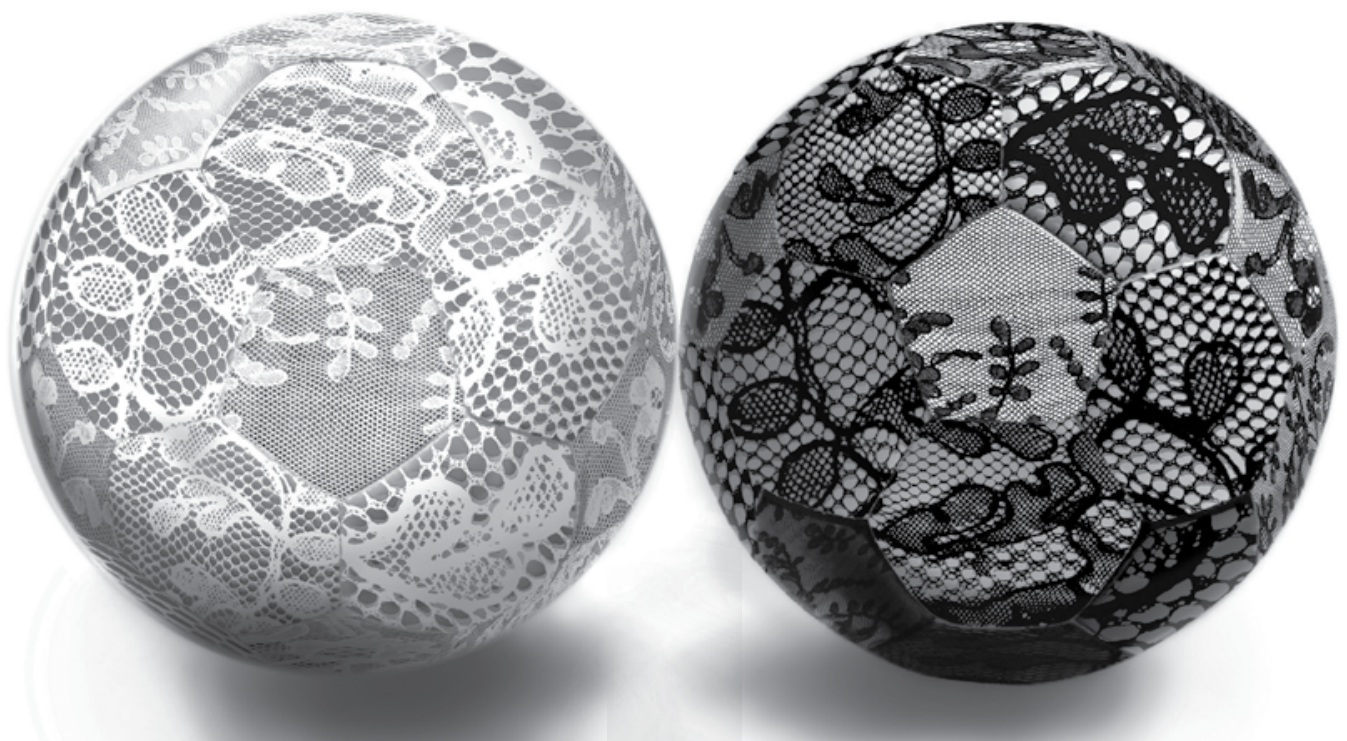


Para gerar a textura tridimensional, as rendas devem ser digitalizadas por meio de escaner de 3D, gerando uma nuvem de pontos que traduz a topografia da superfície a ser transferida através de processos específicos de alteração das características táteis do material, neste caso laminados de PVC (policloreto de vinila) e PU (poliuretano).

0 projeto de design de superfície é enviado on-line para produção em outro país onde a impressão é feita sobre os gomos cortados. Por fim, a montagem: a bola é costurada à máquina e fechada à mão.

\section{Jogando com bola de renda}

Numa "pegada" feminista, o projeto apresentado renuncia à dominação sociocultural do masculino através do vocabulário gráfico dos itens esportivos e propõe inovação para acompanhar o estilo de vida contemporâneo saudável, com humor, sensualidade e alegria.

Assunto reconhecivel mundialmente, 0 tecido de renda revela multiplicidade de sentidos potenciais, apresentando-se como conceito forte, significativo, podendo claramente ser compreendido e admirado por todo o planeta. A proposta de dar a impressão que a bola é "vestida" com rendas coloca o estranhamento da discrepância entre conteúdo e revestimento. Com humor, pretende diluir estereótipos sociais, mitos e clichês sobre gênero e poder, que são comunicados e reforçados pelo sistema de publicidade esportiva de massa hoje em vigor.

0 produto são bolas de renda branca e preta, para serem dadas de presente e/ou jogadas por mulheres, crianças e homens também. Se somos aficionados ou não de futebol ou de outros esportes, não importa, as bolas de renda devem afetar o espirito e o sentimento, enriquecendo-nos como participantes e espectadores do maravilhoso jogo da vida.

\section{NOTAS}

[1] Para saber mais sobre a empresa, consulte: <http://www.peacocksports.com.br>

${ }^{[2]}$ Disponivel em: <http://agitprop.com.br/atualidades_det.php?codeps=NjN8>. Acesso em: 30 abr. 2010.

\section{REFERÊNCIAS}

GORETTI, Nicola. Território fértil. In: SAINT-ÉTIENNE: Cite du Design. São Paulo, CCBB, 2010. Catálogo de exposição, 1 dez. 2009-31 jan. 2010, Centro Cultural Banco do Brasil São Paulo. 